\title{
VER E ANDAR COM \\ TEOLINDA GERSÃO ${ }^{1}$
}

Annabela Rita

(Universidade de Lisboa)

\section{RESUMO}

Neste ensaio, pretende-se observar o modo como o volume de contos Histórias de Ver e Andar (2002), de Teolinda Gersão, se inscreve na obra da autora e na sua estratégia de escrita e de efabulação, organizando-se com uma ciclicidade que evidencia uma arquitectura ensaística. O estudo perspectiva o volume de contos como uma 'exposição', na sequência, aliás, de uma reflexão inter-artes sobre a obra desta autora que Annabela Rita vem desenvolvendo.

PALAVRAS-CHAVE: Literatura Portuguesa, Teolinda Gersão, Inter-artes.

\section{ABSTRACT}

In this essay, we intend to observe how the volume of short stories Histórias de Ver e Andar, by Teolinda Gersão, can subscribe in the author's work and in your strategy of written and fable, with a cyclic organizing which reveals its architecture of essays. The study developing by Annabela Rita perspective the volume of tales as an 'exhibition', which has, in fact, the objective to reflect on the inter-arts work.

KEYWORDS: Literature Portuguese, Teolinda Gersão, Inter-arts. 
“(...)os livros são uma espécie de filmes, (...) só que têm ainda mais poder, porque desde sempre houve palavras mágicas, e ainda não há imagens mágicas.”

Teolinda Gersão

\section{Preambularmente}

\section{(Catálogo da exposição)}

$\mathrm{Na}$ obra de Teolinda Gersão ${ }^{2}$, procedimentos autocitacionais criam nexos subtis de intertextualidade e promovem o efeito de reconhecimento autoral e de continuidade na diversidade. Cada texto surge como que integrado num alongado ciclo de escrita, misto de memorialismo interior e de exercício ensaístico, uma escrita em jeito de escrevivência, de ver e andar, como sinaliza em título... Ciclo de ciclos, informado de uma dimensão simbólica que oscila entre os sentidos lúdico, fantástico, mágico e sobrenatural que também dissolve as fronteiras da sua ficção: o narrativo tradicional, suportado na fluência da voz discursiva, invade esses outros territórios mais marginais a ele, contaminando-se das suas realidades e das suas lógicas.

A perspectiva feminina evidencia-se no universo romanesco, conformada pelo imaginário, pensamento, sensibilidade e intuição, tanto de personagens como de narradoras, em contraponto com a sua homóloga masculina, na obra da autora, como entre ela e o literário em que assim se inscreve ou a arte, em geral.

Ensaística e arquitectonicamente, o discurso ficcional busca no diário as suas imagens mais pregnantes e, com progressiva consistência ontológica, chega a conquistar identidade metaforicamente antropomorfizada e problematizada na voz do narrador d' A Casa da Cabeça de Cavalo (1995a), que lhe sublinha a trajectória, que lhe comenta as hesitações, a opacidade e a capacidade inteligibilizadora, as contradições perspécticas, as reescritas dissimuladas, etc. e que lhe perscruta a origem e a morte, configurando-lhas ficcionalmente. N' Os Teclados (1999), o símbolo culmina a trajectória da ficção na via da metáfora, da reflexividade e da condensação semântica. N' Os Guarda-Chuvas Cintilantes (1984) - Diário Ficcional, parece escamotear-se um plano de escrita sem itinerário, apenas cristalizado em tópica autoral, onde as imagens evocam textos já escritos ou se vão iluminando a cada texto que a autora publica.

Desenvolvendo uma efabulação ensaiada, encenada, o discurso ficcional convoca subtilmente toda uma memória estética em que privilegia a pintura, pela visualidade evidenciadora, dialogando com delidas imagens de outra natureza, configurando-as e transformando-as, invertendo-as, fundindo-as, respondendo-lhes, etc.. Com isso, a série romanesca acaba por se assemelhar a um longo filme onde continuidade e metamorfose se imbrincam.

Na encantatória fluência da voz narrativa, na sua consistência interdiscursiva e na sua reflexão sobre a escrita diversamente encenada na ficção, Teolinda Gersão afirma-se na grande tradição narrativa, buscando-lhe o futuro estético e caldeando essa busca na moderna reflexividade, tangencial à experimentação e à simbolização. 
- você devia escrever um romance, disse ele (...), já viu que desperdício, toda essa imaginação gastando-se nesta conversa, certamente interessante, em pura perda? (GERSÃO, 1995b, p. 114)

- eu procurava um enquadramento, um limite, uma forma, porque estava perdida na multiplicidade das coisas.

(...) porque eu era vaga e difusa e sem fronteiras, igual a tudo e a nada, e havia uma casa que se abria na noite com a sua luza acesa (...) (GERSÃO, 1995b, p. 35)

Na sua galeria ficcional, a reflexão sobre a escrita vai-se vertendo na experiência dela, através de sucessivas encenações de ficções que de si falam, descrevendo-se, afinal, na imagem iconicamente exposta que cintila como esse guarda-chuva "de seda, de vidro, de papel” (GERSÃO, 1997, p. 8), "de espelho" (GERSÃO, 1997, p. 42) que persegue em sonhos e que acaba por "apanh[ar] de repente", ficando na sua mão como "um monte de folhas desmanchadas"(GERSÃO, 1997, p. 8), "prontas para a gráfica, depois de terem estado "espalhadas pela casa", "por todo o lado" sem controlo, pois "a total não interferência fazia parte do pacto que havia entre ela e as folhas de papel" (GERSÃO, 1997, p. 46-47).

E a escrita desenvolve uma permanente sedução. Na sua relação comigo, leitora, procura esclarecer-se através de homologias metafóricas, como é o caso da fotografia: a escrita explicada como processo de "artifícios, armadilhas, para [apanhar e] fazer apanhar a sombra” (GERSÃO, 1997, p. 36). Buscando "o melhor local, o melhor ângulo, o melhor enquadramento, e espreitar pelo visor da máquina", "assegurando-se de que est[á] certa a intensidade e a direcção da luz", e "aprend[er] a ver a luz", "a modelar com a luz" para obter "um efeito de contraste, a sombra recortada contra a luz", uma sombra em fuga. (GERSÃO, 1997, p. 36-37) Mas, por fim, na foto, a autora quer, em última instância, que eu me reconheça e me projecte no ponto-de-fuga em contra-luz com outros fantasmas da arte, sobreimpressa na imagem dela, no seu retrato, confundida com ela, amorosamente fundida:

(...) quero ser por instantes, em fulgurações breves, a mulher que está para lá de todos os teus sonhos, ou ser apenas uma superfície lisa, um espelho, um vidro, onde julgues ver-me, quando olhas apenas a tua face solitária. (GERSÃO, 1997, p. 62)

Na escrita de Teolinda, convoca-se, assim, o fantasma de um mito sobre a invenção da modelagem em argila que Plínio, o Velho, evoca e outros retomam:

Ao utilizar também a terra, o ceramista Butades de Sycione foi o primeiro a descobrir a arte de modelar os retratos em argila; passava-se isto em Corinto e ele deveu a sua invenção à sua filha que se tinha enamorado por um rapaz; como este ia partir para o estrangeiro, ela contornou com uma linha a sombra do seu rosto projectada na parede pela luz de uma lanterna; o seu pai aplicou a argila sobre o escorço, e fez um relevo que pôs a endurecer ao fogo com o resto das suas cerâmicas, depois de o ter secado. ${ }^{3}$ (apud GIL, 2005, p. 17) 
Modelagem, pintura, desenho e retrato parecem, assim, nascer desse amoroso gesto arquetípico de contornar a sombra de um rosto (circumductio umbrae).

- Irei por um caminho de vidro, de pedras, de brilhantes, por um caminho de água iluminada (...).(GERSÃO, 1984, p. 82)

O caminho por onde vou passa por dentro de casas sucessivas, sonho. Como um longo corredor - e no entanto são casas distintas.(GERSÃO, 2002, p. 4)

Mas (...) a todas as perfeições sonhadas falta sempre ainda a perfeição de existir.(GERSÃO, 1984, p. 114)

\section{Exposição}

Do trabalho reiterativo e metamorfoseante da escrita de Teolinda Gersão, que contiguiza imagística e tematicamente os seus textos, resulta, pois, um efeito cinematográfico, espectacular e espectacularizante de movimento e de transformação: imagens, temas, obsessões, fantasmas e um feminino em sistemática re-configuração entretecendo um canto feminino, diurno, solar, que responde ao que, no masculino, crepusculiza a literatura nacional portuguesa.

O ciclo do sol, arrastado pelo "cavalo do tempo" (1989), funde-se com a casa (1995a) e dá lugar à mulher vinda da praia (1995b) e da janela (1996) com que o confunde essa música que o gramafone ou o gira-discos solta do disco negro (1989, 1995b), "talvez Vivaldi" (1995b), libertando-a para (re)nascer como Mozart na criança d' Os Teclados, que no-la oferece como imagem do tecido da obra, das obras. A efabulação (1995b) plasma-se no Génesis bíblico da mesma forma que o convite à leitura se decalca na afectuosidade do Cântico dos Cânticos. A caneta converte-se em guarda-chuva ou em vassoura voadora (1997). A mulher fantasmiza-se na vidraça onde homólogas pictóricas se projectam (1996), protagonizando, depois, com o seu duplo, fantástico cavalo, quadros sonhados pela ficção (1989) ou informados de sonhos de outras ficções (1997) O piano surpreende com a "silhueta escura" na intimidade doméstica (1989) e acaba por dominar um romance (1999), assemelhando-se a "um caixão preto" (imagem da guitarra-caixão do "Fado Hilário", emblemático da boémia coimbrã e desse académico cuja voz e fama ecoam ainda), imaginário ou substituído pela clavinova. Etc..

Dir-se-ia que lê-la é contemplar uma paisagem em metamorfose: uma escrita onde os títulos ensaiam fragmentos de um gesto continuado, de uma ficção em auto-efabulação, encenada no seu curso, convocando paisagens que os excedem, antecedendo-os também, paisagens estéticas onde as artes se respondem (a literatura, o cinema, a pintura, a música), apresentadas por uma reflexão ensaística informada por uma concepção eminentemente teatral da arte. O romanesco insinua-se, assim, como um teatro de sombras de outra(s) representação(ões).

Assim...

Os Teclados parecem encerrar um ciclo, expandindo maximamente uma imagem d'O Silêncio: 
E então ela partia, dentro de si mesma, numa direcção alta e aguda, que de repente se desdobrava numa escala inteira. Como alguém sentado ao piano subitamente descobre as suas mãos sobre o teclado, e as mãos partem, soltas, pelos sons, experimentando todos, combinando-os de cada vez num improviso diferente, enquanto a alegria sobe, funda, e não se sabe se vem da liberdade de correr ou da possibilidade de combinar os intervalos sempre de uma maneira nova. Pequenos espaços em branco, de uma tecla para a outra, hesitando um momento, de pura expectativa. (GERSÃO, 1995b, p. 52)

A promenade pelo teclado insinua a rapsódia de todo o ciclo $^{4}$, "de uma tecla para a outra", mas também da figura feminina que o atravessa reconfigurando-se a cada emergência e da viagem "dentro de si mesma", figura e ficção, paisagem com figura, transversal a esse ciclo, caleidoscópio de espelhos e de transparências. Como num intermitente "corredor", em cujas extremidades uma figura observasse a sua outra imagem ao fundo, reflexo ao espelho ou ao teclado.

Acendeu a luz da entrada e viu-se de repente no espelho - dois momentos sobrepostos no tempo, dois corpos sobrepostos, um corpo no limiar do declínio e um corpo jovem, apressado, trémulo, procurando ainda a sua própria forma. (GERSÃO, 1995b, p. 47)

\section{Promenade (a minha)}

(ao som de outra, que unifica Quadros de uma Exposição (1874) de Mussorgsky, sublinhando o seu passeio de observador à exposição do arquitecto Viktor Hartmann)

$\mathrm{E}$ as teclas desse teclado transparente vão-se autonomizando e cristalizando em texto breve, conto ou...

Histórias de Ver e Andar.

Histórias de ver e andar foi o nome dado pelos árabes às narrativas de viagens, em épocas de descobrir mundos. Mas não é necessário ir longe para mudar de horizonte: o desconhecido mora ao lado, e também dentro da nossa porta.

Reconhecê-lo - ou não - depende do modo de ver.

E do modo de andar. (GERSÃO, 2002, contracapa)

E esse modo é diferente do quotidiano, do habitual, do comum. No andar, como no ver... ou no ouvir, na correspondência perceptiva dos sentidos:

Ouvir era uma absoluta atenção às coisas. Tudo ficava suspenso, no vazio. E depois o som acontecia: a chuva, o vento, o mar. O vento nas folhas, no caminho de terra, nos telhados, na chuva. Agora ela ouvia a chuva, as formas fugidias da água (a música, não a da chuva, a música em si mesma era líquida ou aérea? Líquida, supunha [...]). 
Mas ouvir não era separado de ver, sentir ou entender. Nem se podia ouvir, de cada vez, uma coisa isolada, sem dar conta de que havia em volta um contexto (...) que depois fazia ressaltar, exageradamente nítida nos contornos, cada coisa de per si. (...).

Ouvir era deixar o mundo entrar em si. (...) O som seguia o seu curso e ela deixava de existir separadamente, tornavase parte do que acontecia. O que também era um risco. Quase de morte (...). Porque a música, de algum modo, estilhaçava-a, fazia-a sair de si mesma e arrastava-a para um estádio indiferenciado, não humano, contra o qual a música finalmente triunfava. (...) Enquanto durava (...), a música era uma forma de ultrapassar o caos, obrigando-o a caber numa medida. (GERSÃO, 1999, p. 14-16)

$\mathrm{Na}$ imagem da capa, mesmo antes da leitura do título, sentimos a tradição e a memória popular a caminhar para nós, ao nosso encontro.

Em movimento, a passo cadenciado, os pés fotografados dirigem-se para nós, andam, vendo e fazendo ver com eles, até à consciência do poder mágico da palavra: "Foi assim que descobri como (...) os livros são uma espécie de filmes, (...) só que têm ainda mais poder, porque desde sempre houve palavras mágicas, e ainda não há imagens mágicas" (GERSÃO, 2002, p. 40)

A tradição das narrativas de viagens, legitimando e justificando na viagem o visto e o contado, habitadas pelas maravilhas do desconhecido pela maioria. Como o Itinerário, Viagem ou Navegação de Linschoten:

ITINERÁRIO, VIAGEM OU NAVEGAÇÃO DE JAN VAN LINSCHOTEN PARA AS ÍNDIAS ORIENTAIS OU PORTUGUESAS, incluindo uma breve descrição desses países e costas marítimas, com indicação de todos os principais portos, rios, cabos e lugares até agora descobertos e conhecidos pelos portugueses; ao que se juntam, não só os retratos dos vestidos, trajes e aspecto, tanto dos portugueses aí residentes como dos indianos naturais, e seus templos, ídolos e casas, e igualmente as principais árvores, frutas ervas e especiarias e materiais afins, mas também os costumes destes povos, tanto nas suas religiões, como na política e administração, e ainda um breve relato dos tráficos, de onde e como são tratados e encontrados, com as histórias mais memoráveis que aconteceram aí durante a sua residência, tudo descrito e reunido pelo próprio. Muito proveitoso, apropriado e também divertido para todos os curiosos e amadores de coisas estranhas. (POS; LOUREIRO, 1998, p. 69)

Itinerário, obra informada, como tantas dessa linhagem de escrita, da perspectiva maravilhada e que quer maravilhar, ingénua ou sedutora, que se concretiza exemplarmente num momento da Dedicatória anunciando um relato fabuloso:

Sem dúvida, é digno de espanto que a árvore-triste (como é chamada pelos portugueses nas Índias Orientais) floresça 
a noite inteira e ao amanhecer deixe cair apressadamente a sua flor, de cheiro suavíssimo, começando pelo ano inteiro a florir de novo com o pôr do sol. Ou também (o que é mais raro) que, num certo lugar do reino Anhalt, a terra produza por si própria chávenas tão perfeitas como se fossem formadas na roda do oleiro e as asas colocadas à mão. (POS; LOUREIRO, 1998, p. 63)

Teolinda também nos impõe a memória do contoário que, n’ As Mil e Uma Noites de oriental origem, tem o seu ex-libris mais famoso. Textos inaugurados com o signo inequívoco do "Era uma vez..." que instaura o domínio do encantatório de outro paradigma, universo em que as leis da natureza são outras ou subvertíveis...

Em ambos os casos, está em causa a forma breve consagrada no conto e a função evasiva domina a motivação da leitura, como se assinala na contracapa e em diversos textos deste volume. Forma breve que impõe a capacidade de o fragmentário se constituir em totalidade, a potencialidade de o micro representar o macro que o contém imaginariamente, e de se renovar em permanente metamorfose, de inscrever na identidade autoral a alteridade artística, em jeito de alquimia do verbo, onde estética e sabedoria colectiva se confundem:

Andei ainda a pé (...), recomecei a andar, entrei ao acaso numa galeria onde havia três ou quatro esculturas e alguns quadros. Olhei-os (...). Um deles (...) chamou-me a atenção (...). Representava uma mesa com um cesto de fruta e ao lado uma travessa com búzios, algas, pedras e um peixe enorme, de olho vítreo, em primeiro plano. O título, afixado na parede, com letras minúsculas, era: Natureza Morta Com Cabeça de Goraz.

A seguir (...) voltei para casa (...). Mas sabia que o quadro me voltaria a lembrar e acredito que me vai ficar na cabeça, sem nenhuma razão, até adormecer. (GERSÃO, 2002, p. 157)

O título do conto revela-se glosa de outra obra de autoria desconhecida, talvez inexistente com este exacto título, mas potencialmente múltipla na semelhança.

Segurança desenvolve a vida entre o onírico e os fantasmas da morte temida, antecipada, em cenário que se crepusculiza para acolher o fim do conto e do seu protagonista, fechando o ciclo dessa dupla existência de escrita feita: "Os pássaros recolhiam-se nas árvores, na distância os cavaleiros tinham desaparecido. A noite descia e começou a levantar-se vento." (GERSÃO, 2002, p. 29)

Depois, o universo ficcional oscila e confunde real e onírico, quotidiano e estranho, banal e insólito, insígnias da modernidade e da tradição, numa escrita que se desenvolve enquadrada entre dedicatória (A Dedicatória) e leitura ( $O$ Leitor), projectando-se, reflexivamente, em composição musical e género pictórico que a inscrevem noutras linhagens estéticas: o nocturno (Noctário) e a natureza-morta (Natureza Morta Com Cabeça de Goraz). Daí o estranhecimento e a desorientação ficcionais: "Mas à noite os sonhos voltavam: procurava debalde o caminho (...). Começava a andar, 
(...), mas perdia-me em bifurcações, em caminhos de areia, (...) e não levavam a nenhum lado." (GERSÃO, 2002, p. 115)

Se o nocturno era, originalmente, peça musical a executar a solo em jeito de serenata à noite, a natureza-morta convoca a tradição das vanitas, a evocação da morte inelutavelmente associada à vida, conjugando-se ambas as linhagens para remeter a relação escrita-leitura para a esfera de um ritual em marginalidade do social diurno: a imaginação desdobra universos paralelos, fantasmiza o mundo real a partir da sua própria matéria, cuja plasticidade explora até aos limites das potencialidades perspécticas e construtoras do verbo artístico.

A progressão da vertigem da leitura nas intermitências de cadência hipnótica vividas nos túneis do metropolitano d'O Leitor maquinista, cuja vivência esquizóide acaba por conduzir à perda da consciência proprioceptiva, é, talvez, a metáfora mais expressiva desse ritual:

Não dei conta, embrenhado na leitura não ouvia a voz da gravação [da fita magnética que anunciava as estações de paragem do metro]. Concentrava-me nas linhas, do livro e do comboio, atento à circulação no sentido certo, evitando tudo o que pudesse prejudicar ou atrasar a marcha. Todo eu era olhos, e esqueci os ouvidos, ou eles esqueceram-se de mim e abandonaram-me. (GERSÃO, 2002, p. 188-189)

E outras intermitências este contoário assegura ao leitor de Teolinda Gersão, para além do (ir)reconhecimento do nosso quotidiano, do real comum: o reconhecimento de imagens, flashes desse outro universo que é o seu, autoral, e que se vai fazendo pressentir como filme projectado sob o filme lido, fundo difuso assinalado num outro título (Paisagem com Mulher e Mar ao Fundo), dissolvendo-lhe os contornos da letra no fundo da memória incerta, indecisa, indecidível. Percepção em consciência "sonâmbula" (GERSÃO, 1989, p. 148). A memória de outros textos reaviva-se através de imagens convocatórias. As retomadas: a mulher, a escrita, o(s) sonho(s), a pintura, a fotografia, o guarda-chuva... Ou as transformadas em espelho deformador, como a do teclado vertido em metropolitano: "No comboio e no livro, as linhas eram de certo modo paralelas. Ler também era seguir, por um túnel escuro, e chegar, de quando em quando, a uma plataforma iluminada." (GERSÃO, 2002, p. 190)

No espelho deformador do verbo projectam-se real e arte, autor e leitor, narrador e personagem, imagem ficcional e homóloga artística, humano e animal:

Uma coisa levaria a outra, sem rupturas. (...) Eu tinha feito aquele caminho milímetro a milímetro, os olhos deslizando sobre as linhas do livro, como um bicho lento e voraz.

Também agora o comboio deslizava nas linhas, devoravaas com os seus olhos acesos. Como um bicho rápido e voraz. (GERSÃO, 2002, p. 182)

Na imagística, os opostos sobrepõem-se ("bicho" "lento" e "rápido"), o singular e o plural plasmam-se ("olhos acesos" ou "olho vítreo") e a diferença insinua-se equivalência ("voraz" e "goraz", "leitor" e "comboio", "filme" e "livro", "linhas" do livro e dos carris), manipulando a imaginação até ao "absurdo" (GERSÃO, 2002, p. 183). 
Afinal, no "modo de ver" e "no modo de andar" de Teolinda nestes contos, reconheço a sua obsessiva e maravilhada reflexão sobre a escrita e a leitura gerando uma ficcionalidade eminentemente simbólica na espectacularidade da sua elaboração imagística, metafórica, ensaística5:

(...) na música as frases não aconteciam ao acaso, remetiam umas para as outras, formavam sempre um conjunto (...) como se a música fosse um tecido (...)

No meio de uma frase, um acidente reduzia a metade a distância à nota seguinte, ou, pelo contrário, aumentava-a, uma diferença mínima, que no entanto arrastava pesadas consequências, como se o bater de asas de um insecto fizesse rebentar uma tempestade à distância. $\mathrm{O}$ acenar, longínquo, de outra frase, que sem se saber como se insinuava e subia à superfície e a levava para onde ela não desejava ir, impulsos que se organizavam em frases, ligando-se ou desligandose, temas que pareciam desaparecer como se os tivesse abandonado mas depois voltavam, insidiosamente, aqui e ali, por vezes quase irreconhecíveis (...). (GERSÃO, 1999, p. $28 ; 30-31)$

E, do sonho das Histórias de Ver e Andar, mais "não pôde [a autora] contar, porque desse sonho nunca mais voltou." (GERSÃO, 2002, p. 83) Ver e Andar, pois, com Teolinda Gersão, é sem "caminho de regresso" (GERSÃO, 2002, p. 29), apenas de ida, no plural das partidas e das viagens...

\section{Notas}

1 À obra da autora, dediquei um estudo abrangente que inclúi no meu livro Emergências Estéticas (Lisboa, Roma Editora, 2006): “Teolinda Gersão: a palavra encenada" (p. 123214). Aí sintetizo e concluo muito do que fui observando em análises mais casuísticas.

2 As edições das obras que uso e refiro, às vezes através das iniciais dos títulos, são: $O$ Silêncio (1981), Lisboa, Publicações Dom Quixote, 1995; Paisagem com Mulher e Mar ao Fundo (1982), Lisboa, Publicações Dom Quixote, 1996; Os Guarda-chuvas Cintilantes (1984), Lisboa, Publicações Dom Quixote, 1997; O Cavalo de Sol (1989), Lisboa, Publicações Dom Quixote, 1989; A Casa da Cabeça de Cavalo (1995), Lisboa, Publicações Dom Quixote, 1995; A Árvore das Palavras (1997), Lisboa, Publicações Dom Quixote, 1997; Os Teclados (1999), Lisboa, Publicações Dom Quixote, 1999; Histórias de Ver e Andar (2002), Lisboa, Publicações Dom Quixote, 2002; O Mensageiro e outras Histórias com Anjos (2003), Lisboa, Publicações Dom Quixote, 2003.

3 Plínio, o Velho, História Natural, XXXV, p. 151.

4 Rhapsody in blue (1924) é também a célebre composição de Gershwin (1896-1937) interpretada por essa outra pianista Lydia Jardon, que evoco atrás, a propósito da Lídia d'O Silêncio. Trata-se de uma composição que reúne três elementos fundamentais da música norte-americana: a tradição do piano, o tratamento harmónico da música do teatro de variedades e a atmosfera dos blues afro-americanos.

5 Cf. Annabela Rita. Emergências Estéticas (ensaios), Lisboa, Roma Editora, 2006; “Teolinda Gersão: a palavra encenada”, p. 123-213. 


\section{REFERÊNCIAS BIBLIOGRÁFICAS}

GERSÃO, Teolinda. A Casa da Cabeça de Cavalo. Lisboa, Publicações Dom Quixote, 1995a.

. O Cavalo de Sol. Lisboa, Publicações Dom Quixote, 1989.

1997.

. Os Guarda-chuvas Cintilantes. Lisboa, Publicações Dom Quixote,

. Histórias de Ver e Andar. Lisboa: Publicações Dom Quixote, 2002.

. Paisagem com Mulher e Mar ao Fundo. Lisboa: Publicações Dom Quixote, 1996.

. O Silêncio. Lisboa: Publicações Dom Quixote, 1995b.

. Os Teclados. Lisboa: Publicações Dom Quixote, 1999.

GIL, José. Escritos sobre Arte e Artistas. Lisboa: Relógio d’Água, 2005.

POS, Arie; LOUREIRO, Rui Manuel (ed. e ests.). Itinerário, Viagem ou Navegação de Jan Huygen van Linschoten para as Índias Orientais ou Portuguesas. Lisboa: Comissão Nacional para os Descobrimentos Portugueses, 1998.

RITA, Annabela. Emergências Estéticas (ensaios). Lisboa: Roma Editora, 2006.

(Recebido para publicação em 16/11/2010,

Aprovado em 18/12/2010) 